\title{
Effect of Rho-associated kinase inhibition on actin cytoskeleton structure and calcium response in glioma $\mathrm{C} 6$ cells
}

\author{
Berenika Targos ${ }^{1}$, Paweł Pomorski ${ }^{1}$, Patryk Krzemiński ${ }^{1}$, Jolanta Barańska ${ }^{1}$, \\ Maria Jolanta Rędowicz ${ }^{2}$ and Wanda Kłopocka ${ }^{1 凶}$ \\ ${ }^{1}$ Department of Molecular and Cellular Neurobiology, and ${ }^{2}$ Department of Muscle Biochemistry, Nencki Insti- \\ tute of Experimental Biology Polish Academy of Sciences; Warszawa; Poland; e-mail: w.klopocka@nencki.gov.pl
}

Received: 1 October, 2006; revised: 08 November, 2006; accepted: 16 November, 2006 available on-line: 19 November, 2006

\begin{abstract}
The role of actin cytoskeleton functional state in glioma C6 cell morphology and calcium signaling was investigated through modification of myosin II activity by blocking Rho-associated kinase with the specific inhibitor Y-27632. Treatment of glioma C6 cells with ROCK inhibitor resulted in actin cytoskeleton reorganization and also in the changed shape and distribution of mitochondria. Changes in the distribution of ER, the main calcium store in glioma C6 cells, were not visible. The inhibition of myosin II activity influences the first phase of calcium signaling evoked by agonist, and both phases of thapsigargin-evoked calcium response. We suggest that the observed increase in $\mathrm{Ca}^{2+}$ release from intracellular stores induced by $\mathrm{IP}_{3}$ formation as well as inhibition of SERCA ATPase is at least in part related to severely affected mitochondria. Enhancement of capacitative calcium entry evoked by thapsigargin is probably associated with the reorganization of the acto-myosin II system. ATP-induced calcium response presents no changes in the second phase. We observed that ATP stimulation of Y-27632 pretreated cells leads to immediate morphological rearrangement of glioma $\mathrm{C} 6$ cells. It is a consequence of actin cytoskeleton reorganization: formation of stress fibers and relocation of phosphorylated myosin II to actin filaments. It seems that the agonist-evoked strong calcium signal may be sufficient for myosin II activation and the stress fiber organization. This is the first work showing the dependence between the functional state of the acto-myosin II system and calcium signaling stressing the reversible character of this relationship.
\end{abstract}

Keywords: actin cytoskeleton, calcium transients, RhoA, ROCK, glioma C6

\section{INTRODUCTION}

Increase in intracellular free $\mathrm{Ca}^{2+}$ concentration $\left(\left[\mathrm{Ca}^{2+}\right]_{\mathrm{i}}\right)$ can initiate and modulate many events essential for cell life (Targos et al., 2005). Calcium response in nonexcitable cells is biphasic and consists of calcium release from the endoplasmic reticulum (ER) induced by the primary messenger - inositol1,4,5-trisphosphate $\left(\mathrm{IP}_{3}\right)$ via the $\mathrm{IP}_{3}$ receptors (first phase) followed by calcium influx from extracellular space (second phase). The depletion of calcium stores causes the opening of calcium channels in plasma membrane and $\mathrm{Ca}^{2+}$ entry called "store operated calcium entry" (SOCE) (Putney, 1986; Putney \& Bird, 1993; Berridge, 1995; Clapham, 1995).
Stimulation of P2Y receptors with ATP evokes a transient increase in $\left[\mathrm{Ca}^{2+}\right]_{\mathrm{i}}$ due to release of $\mathrm{Ca}^{2+}$ from intracellular stores via formation of $\mathrm{IP}_{3}$. In contrast thapsigargin, an irreversible inhibitor of the SERCA ATPase, promotes the leak of $\mathrm{Ca}^{2+}$ from ER without $\mathrm{IP}_{3}$ formation. Both physiological agonists and thapsigargin initiate $\mathrm{Ca}^{2+}$ entry into the cell as a consequence of the calcium depletion of the endoplasmic reticulum.

We have previously shown that in glioma C6 cells the stimulation of nucleotide receptors as well as the exposure to thapsigargin initiate a biphasic $\mathrm{Ca}^{2+}$ response compatible with the typical capacitative model of $\mathrm{Ca}^{2+}$ influx (Barańska et al., 1999; Sabała et al., 2001; Czajkowski et al., 2002). Recent

Abbreviations: $\left[\mathrm{Ca}^{2+}\right] \mathrm{i}$, intracellular free $\mathrm{Ca}^{2+}$; BSA, bovine serum albumin; ER, endoplasmic reticulum; IP3, inositol-1,4,5trisphosphate; MLCK, myosin light chain kinase; MBS, myosin-binding subunit; PBS, phosphate-buffered saline; RLC, regulatory light chain; ROCK, Rho-associated kinase; SOCE, store operated calcium entry. 
experiments performed in our laboratory revealed the relationship between calcium signaling and actin cytoskeleton structure in glioma C6 cells (Sabała et al., 2002; Supłat et al., 2004; Pomorski et al., 2005). These results showed that actin cytoskeleton disorganization and in consequence changes in the organelle distribution influence the first and second phase of calcium response.

In all previous experiments the disorganization of the actin cytoskeleton consisted in affecting actin filaments. The present studies show how changes in the cell cytoskeleton architecture caused by affecting actin-myosin II interaction influence the calcium signaling induced by extracellular ATP and thapsigargin in glioma C6 cells.

It is well established that members of the Rho family of small GTP-binding proteins play a central role in the regulation of the actin cytoskeleton organization in different cell types (Ridley \& Hall, 1992; Ridley et al., 1992; Nobes et al., 1995; Van Aelst \& D'Souza-Schorey, 1997; Bishop \& Hall, 2000). Cdc42 leads to extension of filopodia, Rac modulates the accumulation of actin filaments by the plasma membrane, and Rho mediates the assembly of stress fibers and focal adhesion turnover (Burridge \& Chrzanowska-Wodnicka, 1996; Ren et al., 2000).

Proteins of the Rho family act by activation of target proteins that in turn affect their specific substrate proteins. GTP-RhoA binds, for example, to Rho-associated kinase (ROCK) (Leung et al., 1996, Matsui et al., 1996) that phosphorylate several proteins involved in regulating myosins and other actin-binding proteins (Riento \& Ridley, 2003). ROCK affects the actin-myosin II interaction by phosphorylation of both the myosin-binding subunit (MBS) of myosin light chain phosphatase and the myosin regulatory light chains (RLCs) in the absence of $\mathrm{Ca}^{2+}$ (Kimura et al., 1996). Contractility in nonmuscle cells is also regulated by myosin light chain kinase (MLCK) which phosphorylates RLCs in $\mathrm{Ca}^{2+}$-dependent way (Katoh et al., 2001). Under normal conditions these two signaling pathways are thought to be necessary for stress fibers maintenance. Stimulation of the Rho/ROCK pathway promotes actomyosin-based contractility (Fukata et al., 2001; Katoh et al., 2001). When the activity of ROCK is inhibited, cells not only lost their stress fibers and focal adhesions but also cytoplasmic tension.

The role of actin cytoskeleton functional state in glioma C6 cell morphology and calcium signaling was investigated through modification of myosin II activity by blocking Rho-associated kinase (ROCK) with the specific ROCK inhibitor Y-27632, (+)-(R)trans-4-(1-aminoethyl)-N-(4-pyridyl)cyclohexanecarboxamide dihydrochloride.

\section{MATERIALS AND METHODS}

Cell culture. Glioma C6 cells (40-60 passages) were cultured in minimal essential medium (MEM) supplemented with $10 \%$ calf serum, antibiotics (50 $\mathrm{IU} / \mathrm{ml}$ penicillin, $50 \mu \mathrm{g} / \mathrm{ml}$ streptomycin), and $2 \mathrm{mM}$ L-glutamine. Cells were kept in $37^{\circ} \mathrm{C}$ in humidified atmosphere with $5 \% \mathrm{CO}_{2}$. Medium was changed twice a week. Confluent cells were passaged using non-enzymatic cell dissociation solution. Before experiments or staining, cells were grown on glass coverslips for two days.

Measurement of intracellular calcium. Thirty minute before the calcium measurements cells on coverslips were washed once with PBS and once with the solution containing: $137 \mathrm{mM} \mathrm{NaCl}, 2.7 \mathrm{mM}$ $\mathrm{KCl}, 1 \mathrm{mM} \mathrm{Na} \mathrm{HPO}_{4}, 25 \mathrm{mM}$ glucose, $20 \mathrm{mM}$ Hepes ( $\mathrm{pH}$ 7.4), $1 \mathrm{mM} \mathrm{MgCl}, 1 \%$ bovine serum albumin and $2 \mathrm{mM} \mathrm{CaCl}_{2}$ (standard buffer). The cells were than incubated at $37^{\circ} \mathrm{C}$ for $30 \mathrm{~min}$ in the standard buffer with $2 \mu \mathrm{M}$ Fura-2 AM.

At the beginning of the experiment cells were placed in the $\mathrm{Ca}^{2+}$-free buffer, containing $500 \mu \mathrm{M}$ EGTA instead of $2 \mathrm{mM} \mathrm{CaCl}_{2}$. In the $\mathrm{Ca}^{2+}$-free buffer cells were stimulated with agonist or thapsigargin and after $5 \mathrm{~min}$ the $\mathrm{Ca}^{2+}$-containing standard buffer was added to evoke the second phase of the $\mathrm{Ca}^{2+}$ response. For evoking the calcium response $100 \mu \mathrm{M}$ ATP or $100 \mathrm{nM}$ thapsigargin was used.

Thereafter, the coverslips were mounted in a chamber on a Nikon Diaphot inverted-stage microscope equipped with a fluo $\times 40 / 1.3$ NA oil-immersion objective lens. Fura-2 digital fluorescence microscopy was used to determine the changes in intracellular calcium levels, $\left[\mathrm{Ca}^{2+}\right]_{\mathrm{i}}$ (Grynkiewicz et al., 1985). Ludl Lep MAC 5000 filter wheel system loaded with Chroma Inc. Fura-2 filter set was used for illumination of specimens. Images were acquired using Retiga 1300 chilled digital CCD camera (QImaging Inc.). Data processing was carried out using AQM Advance 6 (Kinetic Imaging Inc.) and MS Excel software. All data are expressed as 340/380 nm induced fluorescence of Fura-2 ratio changes against time $(\Delta 340 / 380)$. Each experiment was repeated at least three times and data are expressed as means.

Cell staining. For visualization of ER cells were stained in $1 \mu \mathrm{M}$ ER-Tracker Blue-White DPX, an ER-specific fluorescent probe (Molecular Probes, USA) for $15 \mathrm{~min}$. For visualization of mitochondria cells were stained in $500 \mathrm{nM}$ Mito-Tracker Deep Red, a mitochondria-specific fluorescent probe (Molecular Probes, USA) for $15 \mathrm{~min}$.

The distribution of F-actin and phosphorylated myosin II was examined by indirect immunocytochemistry. We examined cells stimulated with ATP (as a control), incubated with Y-27632 or cytochalasin D and cells pretreated with Y-27632 and then 
stimulated with ATP. Cells were fixed in 3\% paraformaldehyde for $30 \mathrm{~min}$ and then permeabilized with $0.1 \%$ Triton $\mathrm{X}-100$. The fixed cells were rinsed three times with PBS with $0.5 \%$ BSA. The cells were then incubated over night at $4^{\circ} \mathrm{C}$ with monoclonal antibody against phospho-myosin light chain 2 at a dilution 1:20. This was followed by incubation with Alexa Fluor 488-conjugated anti-mouse secondary antibody (Invitrogen) at a dilution of 1:200 for 60 min at $37^{\circ} \mathrm{C}$. For simultaneous assessment of F-actin distribution, cells were additionally stained by Alexa Fluor 546-phalloidin (Invitrogen) for $30 \mathrm{~min}$ at room temperature. After each step of this procedure cells were washed 3 times with PBS. The stain was visualised with the confocal laser-scanning microscope (CLSM) Zeiss LSM 510. For co-localisation measurements double laser and double excitation was used: Argon for $488 \mathrm{~nm}$ excitation and HeNe for $546 \mathrm{~nm}$ excitation $\pm 10 \mathrm{~nm}$ barrier filters. $84 \mu \mathrm{m}$ and $94 \mu \mathrm{m}$ confocal aperture were applied. No cross excitation or fluorescence bleed-through were observed (not shown).

Actin cytoskeleton modification. The actin cytoskeleton was modified by treating cells with RhoA-associated kinase inhibitor and with cytochalasin D. Cells on coverslips were washed twice with standard buffer and incubated with $100 \mu \mathrm{M}$ Y-27632 for $30 \mathrm{~min}$ or with $10 \mu \mathrm{m}$ cytochalasin $\mathrm{D}$ for $1 \mathrm{~h}$ at room temperature.

Microscopic observations. Specimens were sealed in 2\% 1,4-diazobicyclo-[2.2.2]octane (DABCO) in glycerine mounting medium and observed using a Nikon Diaphot inverted microscope, 60/1.4NA objective. Images were collected using Retiga 1300 chilled CCD camera and processed in a PC computer using AQM 6.0 software (Kinetic Imaging).

\section{RESULTS}

\section{Cell morphology and intracellular (actin cytoskeleton) organization}

Cytoskeleton organization was compared in glioma C6 cells immediately after application of ATP - control cells (Fig. 1A-C) and in cells pretreated with the specific ROCK inhibitor Y-27632 (Fig. 1D-F). It should be stressed that there were no visible differences between resting and ATP stimulated control cells.

Control cells had a polygonal shape and were well spread on the substrate (Fig. 1A-C). Actin filaments formed stress fibers and were localized just beneath the plasma membrane (Fig. 1A) forming cortical network. Myosin II stained with monoclonal antibody against phospho-myosin light chain
2 (Fig. 1B) was distributed along stress fibers and under the cell membrane where it also co-localized with actin filaments (Fig. 1C). Numerous dot-like clusters of F-actin seem to be associated with cell adhesion sites (Fig. 1A). Figure 1D-F demonstrates the results of blocking the Rho-associated kinase. Y27632 treatment resulted in strong changes in cell morphology and actin cytoskeleton organization. Cells were rounded with elongated outgrowths although still remained well attached to the substrate. They lost stress fibers, and F-actin was concentrated mainly in the peripheral region (Fig. 1D). Phosphorylated myosin II was distributed uniformly within the cell body (Fig. 1E) and did not co-localize to microfilaments (Fig. 1F).

The assay performed to assess F- to G-actin ratio in glioma $\mathrm{C} 6$ cells treated with Y-27632 showed that ROCK inhibition does not change the amount of F-actin (not shown). The cell F/G actin ratio was measured using "G-actin/F-actin In Vivo Assay Kit" (Cytoskeleton, USA). The result indicates that Rhokinase inhibition does not influence the intrinsic structure of actin microfilaments but modifies the cytoskeletal network function by blocking acto-myosin II interactions.

Reorganization of the actin cytoskeleton is accompanied by the redistribution of calcium signaling involved organelles (Fig. 2). Cells were stained with ER- and mitochondria-specific dyes. In control cells ER and mitochondria were distributed in the whole cytoplasm including the peripheral zone (Fig. 2A and $\mathrm{B})$. Mitochondria presented mostly oblong, elongated shapes (Fig. 2A). ROCK inhibition did not visibly change ER distribution (Fig. 2D) but greatly affected mitochondria causing their fragmentation. Among mitochondrial shapes there were few elongated forms with small, circular or curly ones predominating. Most mitochondria were concentrated around the nucleus (Fig. 2C). Circular mitochondria were completely absent in control cells.

\section{Actin cytoskeleton organization and morphology of cells stimulated with ATP after inhibition of ROCK}

Since the calcium mobilization was induced by extracellular ATP which is known to promote actin network reorganization by triggering a different signaling pathway, we decided to check whether it affects Y-27632 pretreated glioma C6 cells. Figure 1G-I shows cells pretreated with Rho-kinase inhibitor, according to the procedure described in Material and Methods, and fixed one minute after application of ATP. Such a stimulation cause immediate changes in actin network organization and partial recovery of control cell like morphology (compare Fig. 1A-C).

ATP application led to the organization of stress fibers (Fig. 1G) and relocation of phosphorylat- 

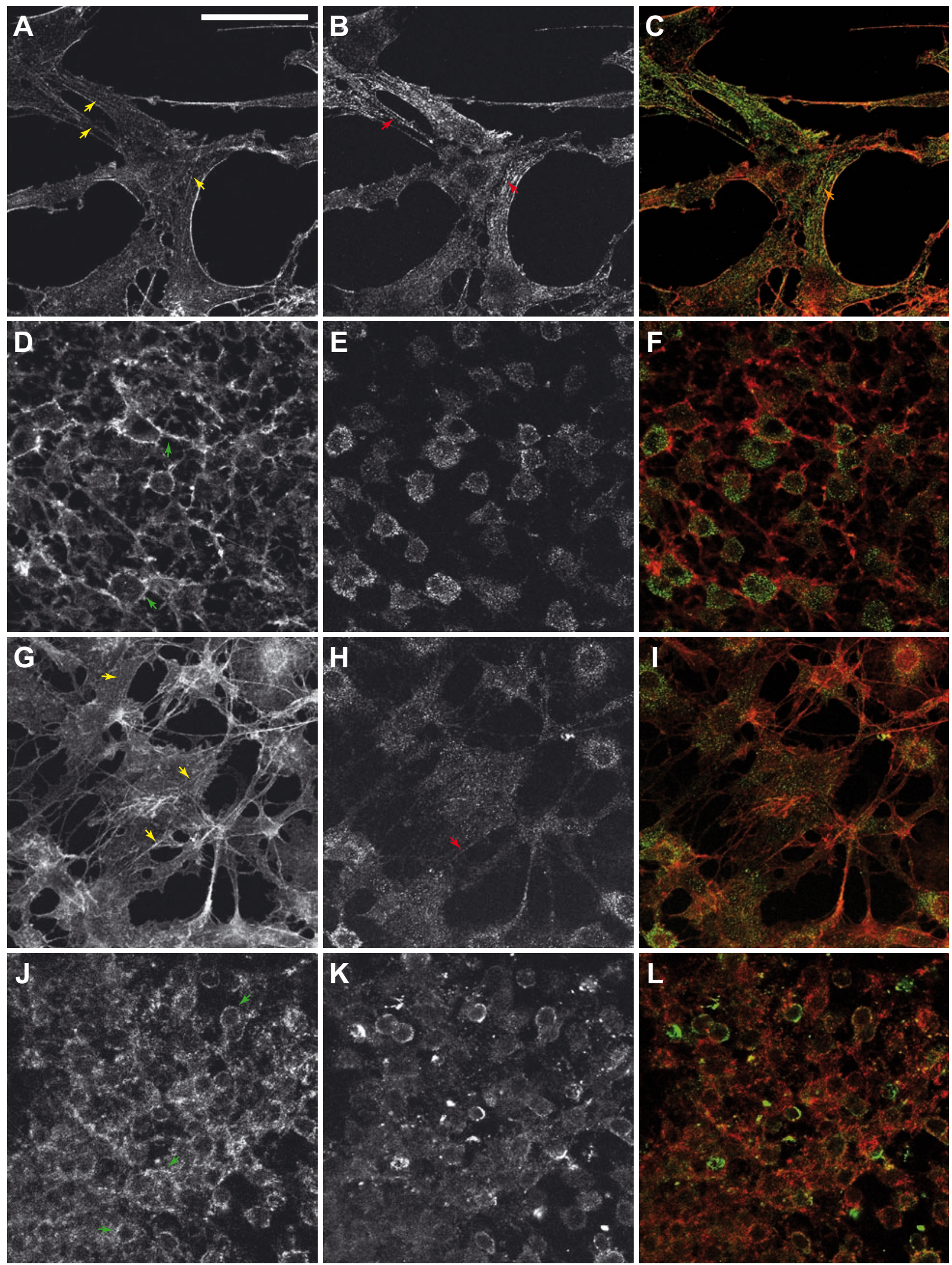

Figure 1. Immunofluorescence localization of F-actin and phosphorylated RLCs in glioma C6 cells stimulated (fixed one minute after stimulation) with extracellular ATP (A, B, C); treated with Y-27632 (D, E, F); pretreated with Y-27632 and after stimulation with ATP $(G, H, I)$, pretreated with cytochalasin D and subsequently stimulated with ATP (J, $\mathrm{K}, \mathrm{L}$ ).

Stress fibers, yellow arrows; phosphorylated myosin, red arrows; actin cortical network, green arrows. Bar: $50 \mu \mathrm{m}$. 

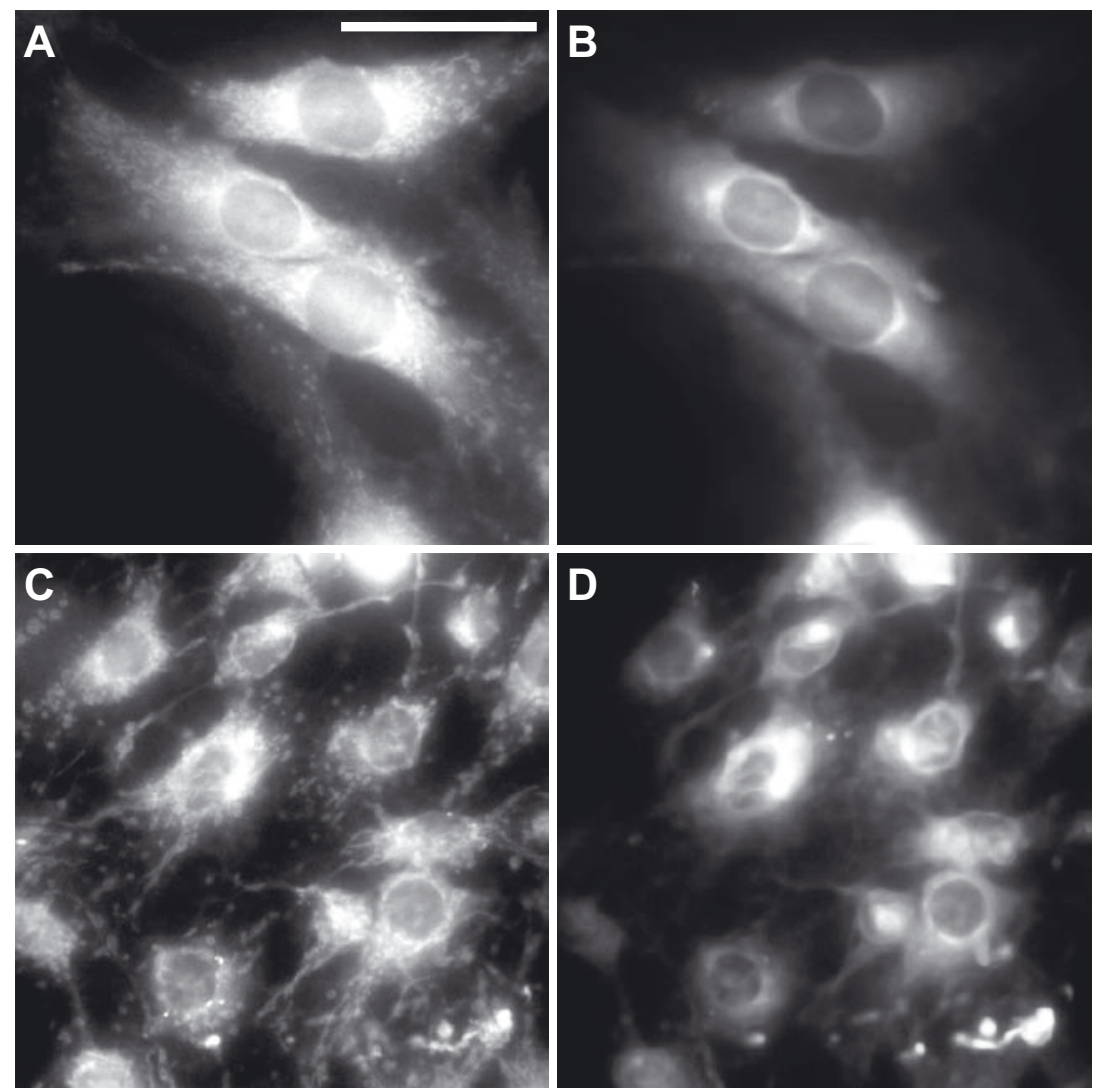

Figure 2. Fluorescence staining of the mitochondria $(A, C)$ and the endoplasmic reticulum $(B, D)$ in glioma C6 cells.

$\mathrm{A}$ and $\mathrm{B}$, control (cultured) cells; C and $\mathrm{D}$, cells treated with Y-27632. Bar: $25 \mu \mathrm{m}$.

ed myosin II to actin filaments (Fig. 1H). Figure 1I shows co-localization of microfilaments and myosin II comparable to that observed in control cells (see Fig. 1C). In contrast, the extracellular application of ATP to cells in which actin filaments were disrupted by cytochalasin $\mathrm{D}$ was unable to rearrange the actin cytoskeleton (Fig. 1J-L). Cells remained rounded with randomly distributed microfilaments (Fig. 1J). In these cells phosphorylated myosin II localized under the plasma membrane (Fig. 1K) and did not co-localize with F-actin (Fig. 1L). These results indicate that activation of $\mathrm{P}_{2} \mathrm{Y}_{2}$ receptors switch on an additional signaling pathway which enable the cell to recover of the normal state only in the case when structure of microfilaments is not disturbed.

\section{Effect of blocking Rho-kinase on calcium signaling}

The next purpose of our work was to check whether and how changes induced in glioma C6 cells by inhibition Rho/ROCK signaling pathway influence calcium response. To assess precisely changes of each phase of calcium response the spatial experimental protocol was used allowing the separation of two phases of calcium signal formation (see Material and Methods).

Y-27632 treatment affected mainly ATP-induced $\mathrm{Ca}^{2+}$ transient resulting from ER calcium release. This release was significantly faster and the maximal $\left[\mathrm{Ca}^{2+}\right]_{\mathrm{i}}$ was about $50 \%$ higher than in control cells (0.59 AU vs. $0.40 \mathrm{AU}$ in control cells, 83
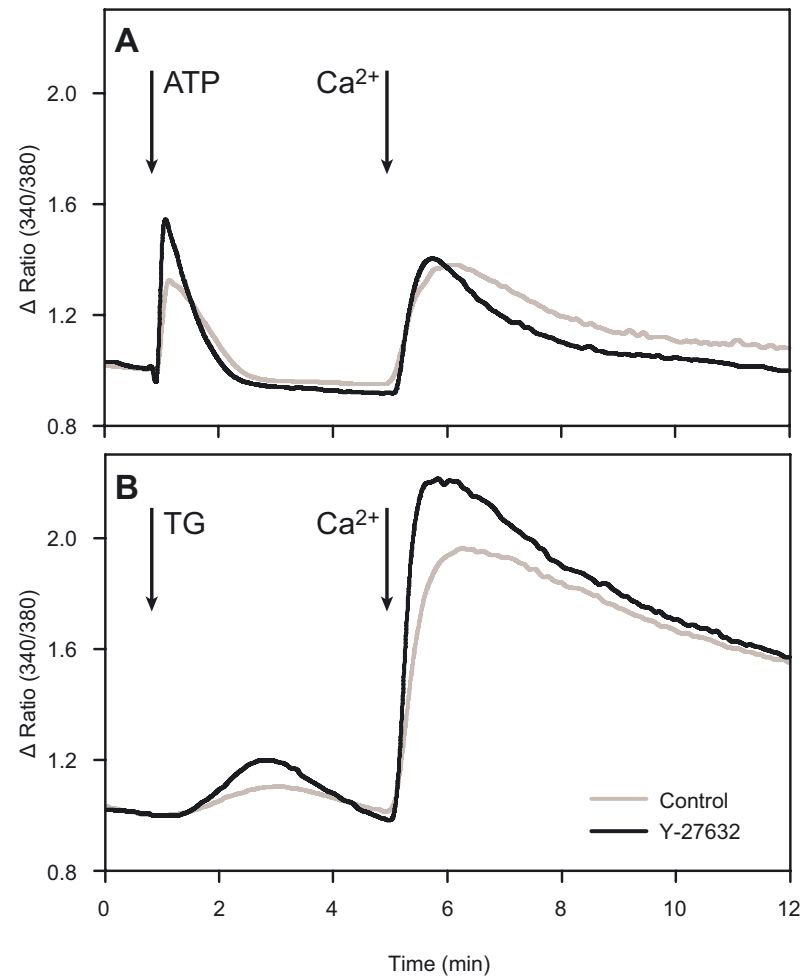

Figure 3. Effect of Y-27632 treatment on intracellular calcium response evoked by ATP (A), and by thapsigargin (TG) (B) in glioma C6 cells.

The cells were incubated with Y-27632, loaded with Fura2 , and treated with ATP or thapsigargin in a buffer containing $2 \mathrm{mM} \mathrm{CaCl}_{2}$ (black lines). The grey lines represent the responses of the control cells with not affected actin cytoskeleton (graphs A, B). The addition of ATP, thapsigargin or $\mathrm{Ca}^{2+}$ is indicated by the arrows. 
and 90 cells respectively, results statistically significant). Also the return to the basal $\left[\mathrm{Ca}^{2+}\right]_{\mathrm{i}}$ level was faster suggesting that the observed changes in transient maximum can be the result of increased transient dynamics (Fig. 3A). The SOCE maximum was not changed (0.50 AU vs. $0.46 \mathrm{AU}$ in control cells, 83 and 90 cells respectively, differences statistically insignificant) but both $\left[\mathrm{Ca}^{2+}\right]_{\mathrm{i}}$ rise and return to the basal value was faster, similarly as in the first phase (Fig. 3A). These results clearly show that changes in the release evoked by agonist do not affect $\left[\mathrm{Ca}^{2+}\right]_{\mathrm{i}}$ resulting from SOCE.

Calcium response evoked by inhibition of SERCA pump with thapsigargin was also changed by ROCK inhibition (Fig. 3B) but the character of these changes was different. Calcium transient during the release phase was faster and higher than in the cells activated with ATP (0.22 AU vs. 0.1 AU in control cells, 40 and 61 cells respectively), but the significant increase was visible in the second phase of the response (1.0 AU vs. 1.25 AU in control cells, 40 and 61 cells respectively).

\section{DISCUSSION}

Blocking of Rho-kinase influences several signaling pathways which regulate myosin II activity and the stability of actin filaments.

In glioma C6 cells treated with Rho-associated kinase inhibitor Y-27632 reorganization of the actin cytoskeleton consists in the disappearance of stress fibers and redistribution of filamentous actin to the submembrane area without influencing the Fto G-actin ratio and re-localization of myosin II from stress fibers and the cortical layer to the cell center (compare Fig. 1C and F). The disappearance of stress fibers may result from the inhibition of myosin II activity as well as ROCK inhibition-dependent cofilin activation (Aber et al., 1998). Blocking of ROCK also causes Rho-dependent Rac activation signaling that is mediated by mDia1 and promotes membrane ruffles formation in fibroblasts (Tsuji et al., 2002). Such a change in signaling pathway activation in glioma C6 cells is probably the reason of the thick, devoid of myosin II, actin rim formation (Fig. 1D, F). Activation of Rac which under normal conditions is antagonized by ROCK may also change the dynamics of cell adhesion (Rottner et al., 1999). Disappeared focal adhesions can be replaced by focal contacts formed at the edges of lamellipodia.

Treatment of glioma C6 cells with ROCK inhibitor also resulted in the changed shape and distribution of mitochondria. However, changes in the distribution of ER, the main calcium store in glioma C6 cells, were not visible (Fig. 2). This is in contrast with the cells treated with cytochalasin D where disorganization of actin cytoskeleton caused a condensation of the endoplasmic reticulum in the perinuclear area and thus altered the spatial relationship between the ER and the cell membrane (Pomorski et al., 2005).

Results presented in this paper revealed that changes in the intracellular organization induced by inhibition of myosin II activity influence the first phase of calcium signaling evoked by agonist (Fig. 3A, B), and both phases of thapsigargin-evoked calcium response (Fig. 3A, B). We suggest that the observed increase in $\mathrm{Ca}^{2+}$ release from intracellular stores induced by $\mathrm{IP}_{3}$ formation as well as inhibition of SERCA ATPase is at least in part related to severely affected mitochondria which are known to be one of the potent modulators of calcium signaling (Rizzuto \& Pozzan, 2006). Enhancement of capacitative calcium entry evoked by thapsigargin is probably associated with the reorganization of acto-myosin II system and in consequence the relationship between cell membrane and the ER structure.

In previous papers we have demonstrated that actin cytoskeleton manipulation can strongly affect the capacitative calcium entry (Sabała et al., 2002; Supłat et al., 2004). Intriguingly, this is not the case in cells treated with ROCK inhibitor, where the ATP-induced calcium response presents no changes in the second phase. We observed that ATP stimulation of Y-27632 pretreated cells led to immediate morphological rearrangement of glioma C6 cells. It is a consequence of actin cytoskeleton reorganization: formation of stress fibers and relocation of phosphorylated myosin II to actin filaments (Fig. 1G-I). This means that agonist-induced capacitative calcium entry in biphasic experimental setup occurred under conditions similar to that in control cells (compare Fig. 1C and I). Strong and fast increase of intracellular calcium level as a result of calcium store depletion probably activates MLCK which under normal condition is necessary, together with ROCK activity, for stress fiber maintenance (Katoh et al., 2001). It is conceivable to assume that agonist-evoked strong calcium signal may be sufficient for myosin II activation and the stress fibers organization.

Extracellular ATP did not induce actin redistribution in cells treated with cytochalasin D, what was also shown in rat adipocytes (Omatsu-Kanbe et al., 2004). Cells remained rounded with uniformly distributed F-actin in the cell body and phosphorylated myosin under the plasma membrane (Fig. 1JL). Under such conditions capacitative calcium entry was significantly decreased (Sabała et al., 2002) what was explained by the disruption of proper spatial relationship between ER and the plasma membrane.

This is the first work showing the dependence between the functional state of acto-myosin II system and calcium signaling stressing the revers- 
ible character of this relationship. The presented results strongly support the hypothesis that the state of the actin cytoskeleton influences the second phase of calcium response and demonstrate that the reorganization of acto-myosin II system can also favor calcium influx. This means that the decrease of contractility can favor a conformational coupling model for store-operated $\mathrm{Ca}^{2+}$ influx.

Our present results show that we must be aware that cytoskeleton functional state and store operated calcium signaling are mutually interconnected. Further studies are needed to understand reciprocal interactions between actin cytoskeleton dynamics and store operated calcium entry.

\section{REFERENCES}

Aber S, Barbayannis FA, Hanser H, Schneider C, Stanyon CA, Bernard O, Caroni P (1998) Nature 393: 805-809.

Berridge MJ (1995) Biochem J 312: 1-11.

Bishop AL, Hall A (2000) Biochem J 348: 241-255.

Burridge K, Chrzanowska-Wodnicka M (1996) Annu Rev Cell Biol 12: 463-518.

Clapham DE (1995) Cell 80: 259-268.

Czajkowski R, Lei L, Sabała P, Barańska J (2002) FEBS Lett 513: 179-183.

Fukata Y, Amano M, Kaibuchi K (2001) Trends Pharmacol Sci 22: 32-39.

Grynkiewicz G, Poenie M, Tsien RY (1985) J Biol Chem 260: 3440-3450.

Katoh K, Kano Y, Amano M, Onishi H, Kaibuchi K, Fujiwara K (2001) J Cell Biol 153: 569-583.
Kimura K, Ito M, Amano M, Chihara K, Fukata Y, Nakafuku M, Yamamori B, Feng J, Nakano T, Okawa K, Iwamatsu A, Kaibuchi K (1996) Science 273: 245-248.

Leung T, Chen XQ, Manser E, Lim L (1996) Mol Cell Biol 16: 5313-5327.

Matsui T et al. (1996) EMBO J 15: 2208-2216.

Nobes CD, Hawkins P, Stephens L, Hall A (1995) J Cell Sci 108: 225-233.

Omatsu-Kanbe M, Shibata M, Yamamoto T, Isono T, Matsuura H (2004) Biochem J 381: 389-396.

Pomorski P, Targos B, Barańska J (2005) Biochem Biophys Res Commun 328: 1126-1132.

Putney JW Jr (1986) Cell Calcium 7: 1-12.

Putney JW Jr, Bird G (1993) Endocr Rev 14: 610-631.

Ren XD, Kiosses WB, Sieg DJ, Otey CA, Schlaepfer DD, Schwartz MA (2000) J Cell Sci 113: 3673-3678.

Ridley AJ, Hall A (1992) Cell 70: 389-399.

Ridley AJ, Paterson HF, Johnston CL, Diekmann D, Hall A (1992) Cell 7: 401-410.

Riento K, Ridley AJ (2003) Nat Rev Mol Cell Biol 4: 446456.

Rizzuto R, Pozzan T (2006) Physiol Rev 86: 369-408.

Rottner K, Hall A, Small JV (1999) Curr Biol 9: 640-648.

Sabała P, Czajkowski R, Przybyłek K, Kalita K, Kaczmarek L, Barańska J (2001) Br J Pharmacol 132: 393-402.

Sabała P, Targos B, Caravelli A, Czajkowski R, Lim D, Gragnanicllo G, Santella L, Barańska J (2002) Biochem Biophys Res Commun 296: 484-491.

Supłat D, Targos B, Sabała P, Barańska J, Pomorski P (2004) Biochem Biophys Res Commun 323: 870-875.

Targos B, Barańska J, Pomorski P (2005) Acta Biochim Polon 52: 379-409.

Tsuji et al. (2002) J Cell Biol 157: 819-830.

Van Aelst L, D'Souza-Schorey C (1997) Genes Dev 11: 2295-2322. 